"Some light has been recently thrown on the illness of Newton by Dr. Dowson, of Whitby, who, at a meeting of the Philosophical Society there on the 3rd of January, 1856, read a paper 'On the Supposed Insanity of Sir. Isaac Newton,' in which he has shown that the malady with which he was afflicted in September I693 was probably influenza or epidemic catarrhal fever, which prevailed in England, Ireland, France, Holland, and Flanders in the four last months of $\mathbf{I} 693$. This distemper, which lasted from eight or ten days to a month, was so general, that 'few or none escaped from it'; and it is therefore probable, as Dr. Dowson believes, that Newton's mental disorder was merely the delirium which frequently accompanies a severe attack of influenza. See Dr. Theophilus Thomson's 'Annals of Influenza or Epidemic Catarrh in Great Britain,' published in 1852 by the Sydenham Society. See also the Philosophical Transactions for 1694, vol. xviii. pp. 105-115." W. GREATHEED.

ABouT forty-five years ago I paid a visit with a friend to the laboratory of the celebrated chemist Prof. Schonbein, the discoverer of ozone in the atmosphere and the cause of influenza. Just prior to our visit the Professor had obtained some ozone, and had inhaled it for the purpose, as he said, of giving himself influenza, in order to ascertain how it would affect him. We both distinctly observed most of the ordinary symptoms of the malady.

I2 Landridge Road, Fulham, January I7.

\section{Rainbow due to Sunlight reflected from the Sea.}

I HAVE never heard of a rainbow, due to the image of the sun in water, having been seen; and I think the following letter, from an old student of mine of sixteen years ago, may interest your readers.

The University, Glasgow, January 7.

ON September 18, 1889, I saw a rainbow, caused, not by the direct rays of the sun, but by their reflection from the sea.

We were at the height of 900 feet; the sky was all clouded except along the western horizon; the sun, an hour before setting, was hidden; but its rays were reflected from the sea. A drizzle was falling, and my companion was remarking how strong the light from the sea was, when it occurred to me that it might give a bow. And there it was behind us-not the usual recumbent bow, less than a semicircle, but an overhanging one, greater than a semicircle. The clouds were drifting from the west, so that the sun came into view; and the usual rainbow became visible with its secondary bow; so that three rainbows were seen at once. The sea-bow and the usual bow were identical at the horizon. The angle between them was greater than the sun's

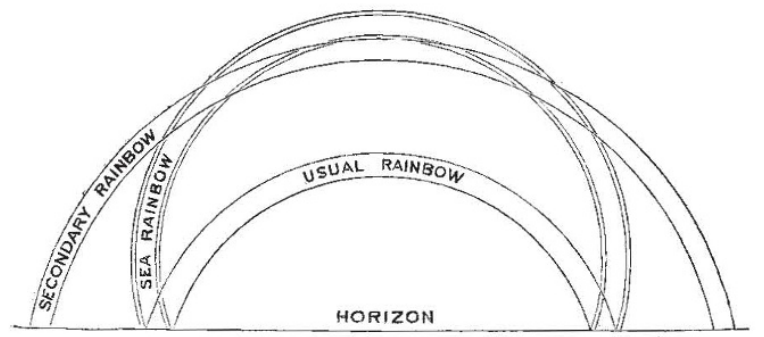

angular height, but not double. It seemed as if the complementary segment of the rim had been folded up from beneath into view, but that the colours were not reversed. The sea-bow was just as bright as the secondary bow, which it intersected.

From the fact that the three were seen together, for over 3 minutes, at least in part, I would argue that it is no unusual sight, and that in Scotland, where bows are so frequent, and plenty of comparatively smooth water available, this sea-bow may be looked for and seen.

I may mention, also, that I saw a fourth bow that evening. After the sun had set, a bow of one colour, an orange-pink, took the place of the usual bow. The source of light, I thought, was a cloud just over the place where the sun had set.

William SCOUlLER.

\section{Osteolepidæ.}

YouR reviewer R. L. is mistaken in condemning so absolutely the above form. The word "Osteolepus" would be a legitimate adjective expressing the same idea as the substantive Osteolepis ; and the patronymic of the "Osteolepi" would be simply "Osteolepidæ," and not " Osteolepididæ."

It may be useful for R. L. and some others to apprehend this principle in word-building-viz. that compound Greek adjectives do not take the lengthened genitive as root; thus the correct Latin equivalent for the corresponding Greek adjective is not "echinodermatus" but "echinodermus," not "distomatus" but "distomus." Hence, the correct form for the neuter plural of the former is "Echinoderma ;" and for the neuter singular of the latter is Distomum. And it would be wrong to write "Distomatidæ" as the family name, and correct to write "Distomidæ." Hence Osteolepidæ and the like are admissible, since they may be considered as formed from adjectives, and not from the substantive (of questionable form itself) in -is,

$$
\text { R. L. + E. }
$$

\section{Exact Thermometry.}

Since the publication of my letter in NATURE (December I9, 1889 , p. 152) on the cause of the rise of the zero-point of a thermometer when exposed for a considerable time to a high temperature, two letters on the same subject have appeared, one from Mr. Herbert Tomlinson (January 2, p. I98), the other from Prof. E. J. Mills (January 9, p. 227), who replies to my objections to the plastic theory.

Mr. Tomlinson considers that my experiments seem to leave no doubt that compression, due to the plasticity of the glass, is not the main cause of the rise of the zero-point, but he considers that it is not merely the prolonged heating, but also the change of temperature (heating or cooling), that is effective in bringing about the change. I have not yet had time to make any special experiments to test this point, but I may perhaps mention that such data as I possess seem rather to point to the conclusion that long-continued steady heating is more effective than alternate heating or cooling. As the following experiment, made about a year ago, seems to bear on the point, I give the results :-

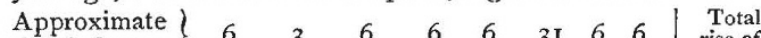
time in hours. $\quad$\begin{tabular}{lllllllll|l}
6 & 3 & 6 & 6 & 6 & 31 & 6 & 6 & $\begin{array}{c}\text { rise o } \\
\text { zero }\end{array}$
\end{tabular}

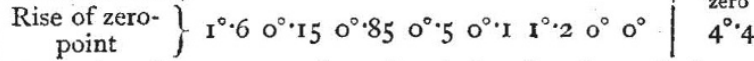
Two other thermometers, heated each day for about six hours, showed after nine days rises of zero-point of $3^{\circ} \cdot 8$ and $4^{\circ} \cdot 1$ respectively, but in these cases the change was apparently not quite complete. The temperature was in each case $280^{\circ}$, and all these thermometers belonged to the same batch as those employed in my experiments already described in NATURE.

Prof. Mills does not regard the experiments as conclusive, but criticizes my results in the following words: "The zero movement, however, only ranged from $I^{\circ}$ to $I^{\circ} \cdot 2$-small readings which might very possibly have been obtained, or not, on either of the thermometers at other times." This criticism, in striking contrast to the rest of the letter, appears to be rather unkind either to me or to my thermometers, I hardly know which. I sincerely hope that none of my thermometers are capable of such erratic behaviour as to show changes of zero-point of $\mathbf{I}^{\circ}$ (or even twice this amount if the plastic theory is correct) without extraordinary treatment, or that my readings of temperature are reliable only to within $I^{\circ}$ or so. But to make the matter more certain, I will continue the heating of the two thermometers, A and $\mathrm{C}$, under the same conditions as before, and will also heat two more thermometers under similar conditions to about $360^{\circ}$.

Prof. Mills mentions the very curious behaviour of lead-glass thermometers at different temperatures, but his objection on that score to the temperature $280^{\circ}$ does not seem to apply, as my thermometers are all made of soft German soda-glass. It may, however, be useful to heat two more thermometers to a temperature of about $220^{\circ}$ in order to compare the total rise with that at $280^{\circ}$ and $360^{\circ}$.

With regard to the statement that the final state of a thermometer kept at the ordinary temperature for an infinite time would differ from that of the same thermometer after being subjected to prolonged heating at a high temperature, I am not prepared to give a decided opinion either one way or the other, but it does appear to me to be rather a daring procedure to make observations of the minute changes of zero-point over a few years, and to extrapolate from a decade or so to eternity. 